\title{
Wnts in action: from synapse formation to synaptic maintenance
}

\author{
Ellen M. Dickins and Patricia C. Salinas* \\ Department of Cell and Developmental Biology, University College London, London, UK
}

\section{Edited by:}

Juan P. Henríquez, Universidad de

Concepcion, Chile

Reviewed by:

Michela Matteoli, University of Milano, Italy

Lorena Varela-Nallar, Universidad

Andrés Bello, Chile

Elisabetta Menna, Consiglio Nazionale

delle Ricerche, Italy

\section{*Correspondence:}

Patricia C. Salinas, Department of

Cell and Developmental Biology,

University College London, London

WC1E 6BT, UK

e-mail:p.salinas@ucl.ac.uk
A proper balance between synapse assembly and disassembly is crucial for the formation of functional neuronal circuits and synaptic plasticity in the adult brain. During development, synaptogenesis generates a vast excess of synapses, which are subsequently eliminated. Importantly, aberrant synaptic disassembly during development underpins many neurological disorders. Wnt secreted proteins are robust synaptogenic factors that regulate synapse assembly and function in the developing and mature brain. Recent studies show that Wnt blockade with the antagonist Dickkopf-1 (Dkk1) induces the rapid disassembly of synapses in mature neurons. Importantly, Dkk1 mediates synaptic loss induced by Amyloid- $ß$, a key pathogenic molecule in Alzheimer's disease (AD). These findings provide new insights into the potential contribution of dysfunctional Wnt signaling to synaptic loss observed in neurodegenerative diseases. In this review, we discuss the role of Wnt signaling in vertebrate synaptic assembly, function and maintenance, and consider how dysfunction of Wnt signaling could contribute to synaptic disassembly in neurodegenerative diseases such as AD.

Keywords: synaptogenesis, synapse disassembly, synaptic plasticity, Frizzled, Dvl, LTP, neurodegenerative disease

\section{INTRODUCTION}

During early development, Wnts regulate critical cellular processes such as cell proliferation and cell fate, neuronal polarity and migration. In addition, Wnts modulate dendritogenesis, axon guidance and synaptogenesis (Ciani and Salinas, 2005; Ille and Sommer, 2005; Rosso et al., 2005; Salinas and Zou, 2008; Budnik and Salinas, 2011; Park and Shen, 2012; Salinas, 2012). The array of diverse cellular processes regulated by Wnt signaling is achieved through multiple Wnt ligands interacting with numerous receptors and co-receptors that trigger distinct signaling cascades that induce local changes and/or global changes through the modulation of target gene expression (Mikels and Nusse, 2006; Kikuchi et al., 2007; van Amerongen and Nusse, 2009). Additional levels of complexity are conferred by the temporal and spatial expression of secreted regulatory factors, which antagonize or activate specific Wnt pathways, or act as a switch between different Wnt pathways. Several excellent reviews on Wnt signaling pathways and their cellular outcomes are available (Logan and Nusse, 2004; Kohn and Moon, 2005; Gordon and Nusse, 2006; Kikuchi et al., 2007; Angers and Moon, 2009; van Amerongen and Nusse, 2009). Therefore, the different Wnt pathways will not be discussed here.

Studies in the past decade have demonstrated that Wnts are key synaptic organizers that play a critical developmental role in establishing neural circuits. The formation of functional synapses requires the precise assembly of pre- and postsynaptic sites in perfect apposition. This process ultimately depends upon the molecular dialogue between the pre- and postsynaptic sides (Figure 1). Indeed, Wnt factors are key players that signal to both pre- and/or postsynaptic sites to promote synapse assembly, morphology and function (Hall et al., 2000; Krylova et al., 2002; Ahmad-Annuar et al., 2006; Cerpa et al., 2008; Davis et al., 2008; Henriquez et al., 2008; Farias et al., 2009; Gogolla et al., 2009; Cuitino et al., 2010; Varela-Nallar et al., 2010; Ciani et al., 2011). Wnts, their cognate receptors and several signaling components continue to be expressed in the adult brain, suggesting a role for Wnts in the mature nervous system. Whilst the function of Wnt signaling in the adult is less understood, recent studies indicate a role in synapse maintenance and plasticity (Chen et al., 2006; Gogolla et al., 2009; Cerpa et al., 2011; Ciani et al., 2011; Purro et al., 2012).

Here we discuss the role of Wnt signaling in synapse formation and maintenance. We will first review how Wnts contribute to synapse assembly and function, focusing on the mammalian central nervous system. This prologue is important to highlight the importance of Wnt signaling at the synapse and the consequence of Wnt blockade or Wnt dysfunction on synapse instability observed in certain neurodegenerative diseases.

\section{PRESYNAPTIC REMODELING}

As axons enter into their target field, they undergo extensive modeling. Studies in cerebellar mossy fiber axons and dorsal root ganglion cells (DRGs) reveal that Wnt signaling activates a divergent-canonical pathway through Disheveled (Dvl) resulting in the inhibition of Glycogen synthase kinase-3 B (Gsk3ß) to regulate axonal remodeling (Lucas and Salinas, 1997; Lucas et al., 1998; Krylova et al., 2002; Purro et al., 2008). This pathway is independent of transcription and induces profound changes in growth cone size and axonal microtubule dynamics by affecting Gsk3 $\beta$-mediated phosphorylation of microtubule-associated 
A

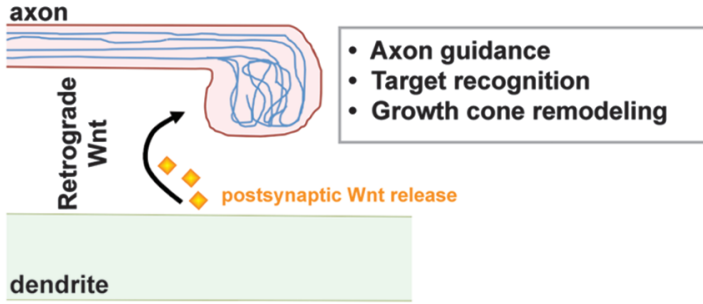

B

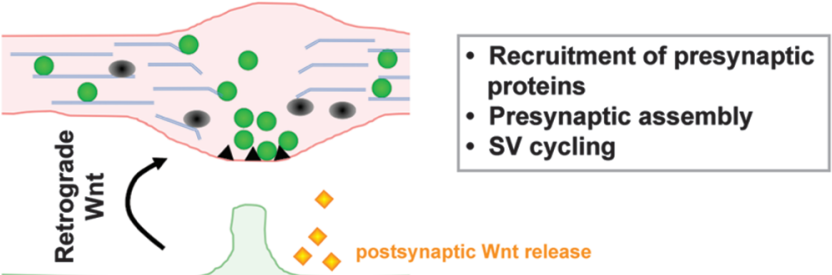

Recruitment of presynaptic

- Presynaptic assembly

(n)

C

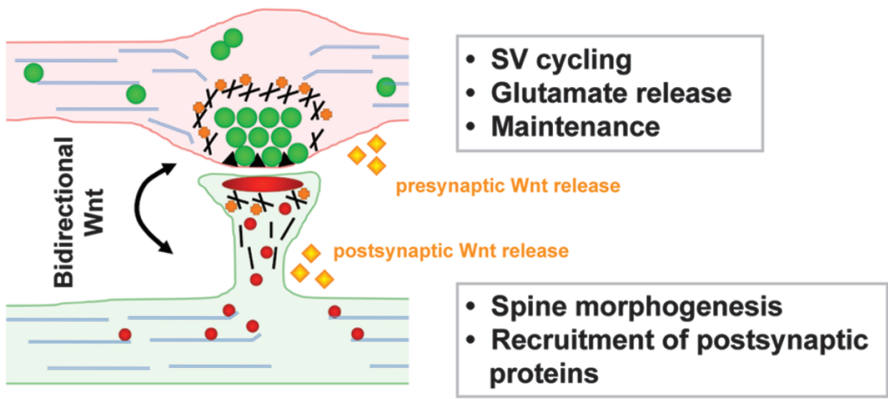

D
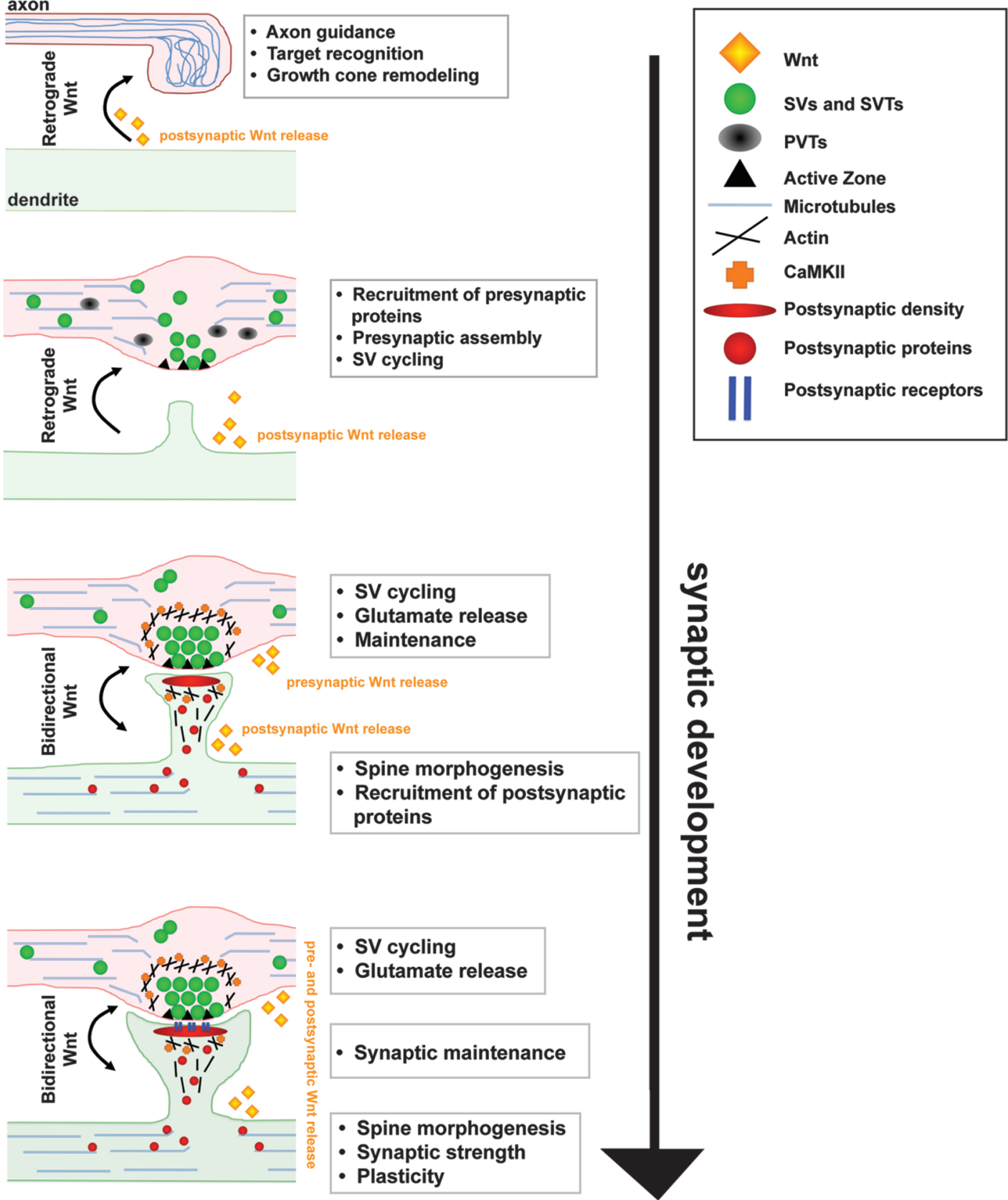

0
$\frac{3}{0}$
$\frac{0}{0}$
$\frac{6}{2}$
$\frac{2}{10}$
$\frac{0}{0}$
$\frac{3}{10}$
$\frac{1}{2}$

FIGURE 1 | A model for the function of Wnt signaling during synapse development and maintenance. (A) Target derived Wnt signals guide incoming axons and induce axon and growth cone remodeling by

modulating the cytoskeleton. (B) Wnt signals directly to the axon through a divergent canonical pathway to stimulate the recruitment of presynaptic proteins resulting in the formation of synaptic boutons. (C) Wnt also signals directly to the postsynaptic dendrite through CaMKII to stimulate spine morphogenesis, postsynaptic protein recruitment and synaptic strength (D) At mature synapses, Wnt signaling regulates synaptic function and maintenance. proteins, such as MAP1B, and the localization of Adenomatous polyposis coli (APC) (Ciani et al., 2004; Salinas, 2007; Purro et al., 2008). APC, in addition to being a component of the canonicalWnt signaling destruction complex, is a microtubule plus-end binding protein that captures the distal end of microtubules to the leading edge of the growth cone (Galjart, 2005). During axon remodeling, Wnt3/3a signals through Dvl1 to inhibit Gsk3 $\beta$ resulting in the loss of APC from microtubule plus ends. Wntinduced APC loss from microtubules results in the loss of directionality of microtubule growth and the subsequent formation of lopped microtubule within growth cones (Purro et al., 2008). These looped microtubules provide a structural mechanism for 
capturing molecules required for presynaptic differentiation and the transformation of motile growth cones into presynaptic boutons. Further studies are required to determine how microtubule dynamics and their organization contribute to early stages of presynaptic differentiation and whether Wnts regulate microtubule dynamics, not only at growth cones, but also at the axon shaft to promote the formation of en passant synapses.

\section{PRESYNAPTIC ASSEMBLY}

Several Wnts promote the assembly of presynaptic release sites. Wnt7a/b and Wnt3/3a stimulate the accumulation of a number of functionally diverse presynaptic proteins including Synapsin 1, vGlut1 and Bassoon, as well as synaptic vesicles (SVs) (Hall et al., 2000; Ahmad-Annuar et al., 2006; Cerpa et al., 2008; Ciani et al., 2011; Figure 2). In contrast, blockade of Wnt signaling by secreted frizzled-related proteins (Sfrps) or Dickkofp-1 (Dkk1) inhibits the ability of $\mathrm{Wnt7a} / \mathrm{b}$ to induce presynaptic protein clustering (Ahmad-Annuar et al., 2006; Davis et al., 2008). Critically, mice deficient in Wnt7a and/or Dvll display significant defects in presynaptic protein clustering (Hall et al., 2000; Ahmad-Annuar et al., 2006). Time-course analyses reveal that Wnt7a/b induces synaptic protein clustering within $15 \mathrm{~min}$ demonstrating a rapid synaptogenic effect (Ahmad-Annuar et al., 2006; Ciani et al., 2011). Furthermore, Wnts rapidly increase the number of functionally active presynaptic sites without affecting total levels of synaptic proteins (Ahmad-Annuar et al., 2006; Cerpa et al., 2008; Varela-Nallar et al., 2009). These findings suggest that Wnts induce presynaptic assembly by promoting the recruitment of existing synaptic proteins and SVs.

Signaling through the seven transmembrane Frizzled $(\mathrm{Fz})$ receptors promotes presynaptic organization. Wnt3a and Wnt7a bind to the Fz1 and Fz5 receptors, respectively, to stimulate presynaptic assembly (Varela-Nallar et al., 2009; Sahores et al., 2010). Both receptors localize at synapses and stimulate the clustering of active zone components and SVs. Moreover, loss of Fz1 or Fz5 function by using the respective soluble cysteinereach domains (CRD) or shRNA-mediated knockdown of Fz5 blocks Wnt-mediated presynaptic assembly (Varela-Nallar et al., 2009; Sahores et al., 2010). In addition to Fz receptors, Wnts can regulate presynaptic assembly by binding to other receptors. For example, Wnt5a binds to Ror tyrosine kinase receptors to stimulate Synaptophysin clustering in cultured hippocampal neurons (Paganoni et al., 2010). Further studies are required to determine whether different Wnt isoforms selectively bind with specific receptors to regulate distinct aspects during synapse assembly.

Wnt signals via a divergent canonical pathway that is independent of transcription, to stimulate presynaptic assembly. A number of findings support this conclusion. Firstly, blockade of canonical-Wnt signaling at the receptor level by the secreted antagonist Dkk1 prevents Wnt-induced presynaptic differentiation (Davis et al., 2008). Secondly, expression of Dvl1, which localizes to presynaptic sites, is sufficient to induce clustering of presynaptic proteins and to promote the formation of functional neurotransmitter release sites (AhmadAnnuar et al., 2006). In contrast, neurons from Dv11 null mice exhibit fewer neurotransmitter release sites and respond poorly to exogenous Wnt7a/b (Ahmad-Annuar et al., 2006).

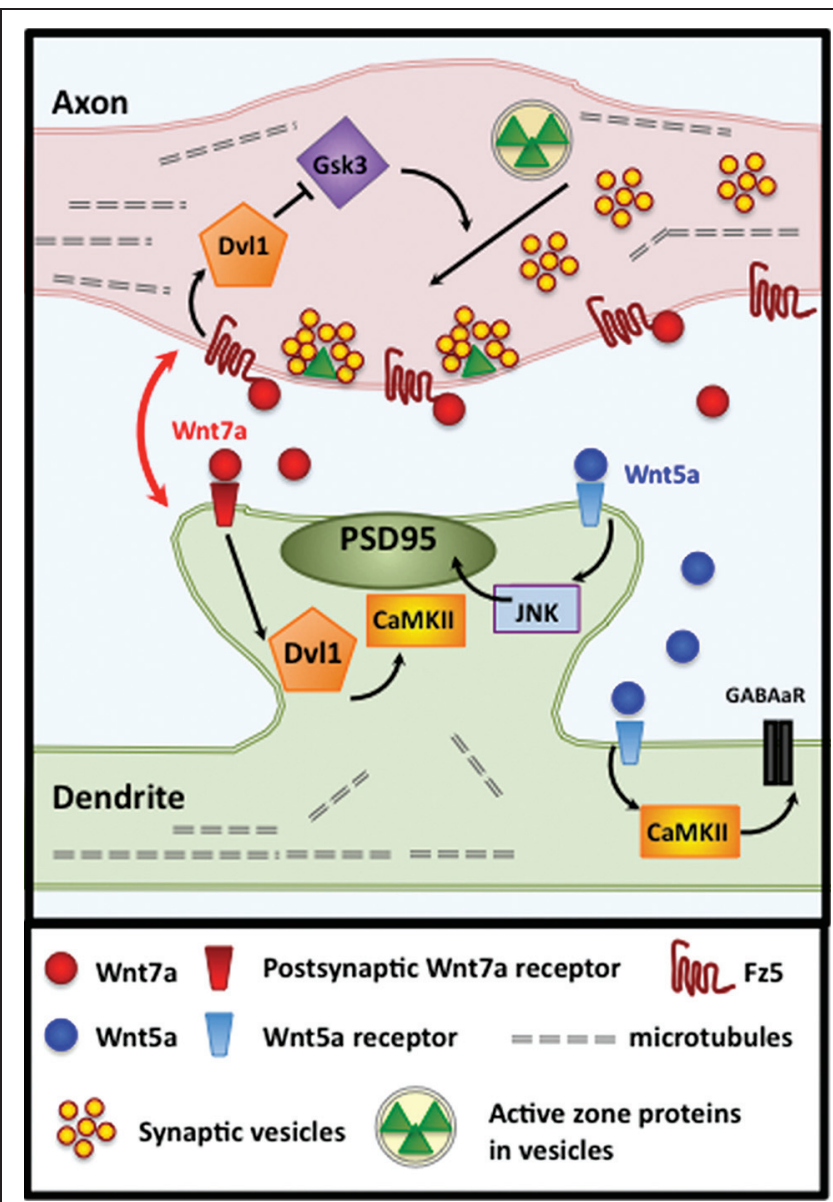

FIGURE 2 | Wnt7a signals bi-directionally at vertebrate synapses. At hippocampal synapses, coordinated bidirectional Wnt7a signaling regulates synapse assembly, development and maintenance. In the axon, Wnt7a binds with Fz5 to activate a divergent-canonical pathway through Dvl1 and Gsk3 $\beta$ that promotes the recruitment of synaptic components, including SV and active zone proteins. In postsynaptic dendrites, Wnt7a promotes spine morphogenesis, PSD-95 recruitment and synaptic strength by signaling via Dvl1 and CaMKII. The postsynaptic Wnt receptor has yet to be determined. Wnt5a signals postsynaptically to promote PSD95 clustering via JNK activation and $\mathrm{GABA}_{\mathrm{A}}$ receptor clustering via CaMKII. The postsynaptic Wnt5a receptor has yet to be identified.

In the canonical-Wnt pathway, activation of Dvl1 inhibits the serine/threonine kinase Gsk3 $\beta$, which phosphorylates and targets $\beta$-catenin for degradation. Gsk3 $\beta$ is expressed presynaptically and its pharmacological inhibition mimics Wnt-induced clustering of synaptic components (Lucas and Salinas, 1997; Hall et al., 2000; Ahmad-Annuar et al., 2006; Davis et al., 2008). Together these findings support a role for the canonical Wnt signaling pathway in presynaptic assembly. However, blockade of transcription by RNA polymerase inhibition does not affect Wnt mediated presynaptic assembly (EM Dickins and PC Salinas, unpublished results) neither axonal remodeling, a process that precedes presynaptic assembly (Purro et al., 2008). These results suggest that Wnt might signal locally to regulate Dvl1 and Gsk3 $\beta$ to promote presynaptic assembly. 
How does Wnt signaling promote the assembly of synaptic boutons? Previous studies have shown that a divergent-canonical Wnt pathway regulates microtubule dynamics in the axon shaft and the growth cone to induce axonal branching, growth cone spreading, and changes in bouton morphology; such effects depend upon profound changes in microtubule organization (Lucas and Salinas, 1997; Hall et al., 2000; Purro et al., 2008). Thus, local regulation of microtubule dynamics by Wnts could provide a possible mechanism for directed delivery of synaptic components to future synaptic sites. While this model is consistent with the changes observed in the formation of terminal boutons, most synapses in the central nervous system are en passant. Therefore, it remains to be determined how en passant boutons become assembled. Interestingly, Wnts seem to promote microtubule unbundling along the axon shaft in some neurons suggesting that changes in microtubule organization might contribute to the initial recruitment of synaptic components to future synaptic boutons. Further studies are required to determine the mechanisms by which Wnt signaling stimulates the rapid recruitment of presynaptic proteins.

\section{POSTSYNAPTIC ASSEMBLY}

Wnts also signal to dendrites to promote the recruitment of postsynaptic components (Cerpa et al., 2008; Henriquez et al., 2008; Farias et al., 2009; Cuitino et al., 2010; Ciani et al., 2011; Jensen et al., 2012; Figures 1, 2). Interestingly, different Wnt isoforms specifically regulate the assembly of excitatory and/or inhibitory synapses. Wnt7a exclusively stimulates the formation of excitatory synapses, without affecting inhibitory synapses (Ciani et al., 2011). Wnt7a stimulates PSD95 recruitment and the apposition of excitatory pre- and postsynaptic markers (Ciani et al., 2011). Wnt7a promotes excitatory synapse formation by inducing the formation and growth of dendritic spines, structures that primarily receive excitatory inputs. Conversely, $W n t 7 a$; Dvl1 mutant mice exhibit significant deficits in spine number and morphology in the Cornus Ammonis (CA) CA1 and CA3 regions of the hippocampus (Ciani et al., 2011). These mice also exhibit reduced frequency and amplitude of alpha amino-3-hydroxyl5-methyl-4-isoxazolepropionic acid receptor (AMPAR)-mediated miniature excitatory postsynaptic currents (mEPSCs). Although the mechanism by which Wnt7a increases spine number remains to be elucidated, spine growth is induced through Dvl1 and local activation of CaMKII at dendritic spines (Ciani et al., 2011).

In contrast to Wnt7a, Wnt5a acts as a pan-synaptogenic factor that stimulates PSD95 clustering at excitatory synapses via JNK activation (Farias et al., 2009) and $\gamma$-aminobutyric acid type A $\left(\mathrm{GABA}_{\mathrm{A}}\right)$ receptor clustering at inhibitory synapses through CaMKII signaling (Cuitino et al., 2010; Figure 2). Whilst some of the signaling mechanisms by which Wnts promote postsynaptic assembly have been identified, many questions remain unanswered. For instance, the identity of the postsynaptic receptors for Wnts and the mechanisms that regulate the formation of different types of synapses are currently unknown.

The precise role of Wnt5a in synaptic assembly remains poorly understood. Wnt5a has been reported to stimulate spine formation via calcium signaling in cultured hippocampal neurons (Varela-Nallar et al., 2010). However, these results have not been consistently recapitulated in brain slices (Cerpa et al., 2011), and another group reported that Wnt5a inhibits excitatory presynaptic assembly (Davis et al., 2008). The reason for these apparent opposing results is unclear at present. Possible explanations could be the age and/or type of neuronal preparation studied, different sources of Wnt5a (recombinant versus conditioned media from Wnt5a-expressing cells), the concentration used or the exposure time. Further work is required to gain insight into the function of Wnt5a as a positive or negative regulator of excitatory synaptogenesis, and how Wnt5a stimulates postsynaptic differentiation of both excitatory and inhibitory synapses, whereas Wnt7a only promotes excitatory synapse formation.

\section{BIDIRECTIONAL WNT SIGNALING}

A number of studies have shown that Wnts can signal in an anterograde and retrograde manner. For example, at the neuromuscular junction (NMJ), Wnt release from motoneurons regulates postsynaptic differentiation on muscle cells (Krylova et al., 2002; Packard et al., 2002; Henriquez et al., 2008; Jensen et al., 2012). In contrast, in the cerebellum, Wnt7a/b is released from postsynaptic cells to regulate presynaptic assembly and remodeling (Hall et al., 2000). In the hippocampus, several Wnts are expressed but the exact source of Wnts at the mossy fiber-granule cell (MF-GC) and Cornus Ammonis (CA3-CA1) synapse remains poorly understood. Recent studies suggest that Wnt7a/b protein is present in the Dentate Gyrus (DG), CA3 and CA1 neurons (Gogolla et al., 2009; Ciani et al., 2011). However, where and how Wnts are secreted to regulate synapse formation and function remains to be elucidated.

Coordinated bidirectional signaling contributes to Wnt mediated synaptic assembly. At the Drosophila NMJ, the Wnt family member Wingless (Wg) signals to both sides of the synapse (Packard et al., 2002; Ataman et al., 2008). Similarly, at hippocampal synapses, Wnt7a acts bidirectionally on axons and dendrites suggesting a conserved role for bidirectional Wnt signaling in synapse assembly between vertebrates and invertebrates. However, pre- and postsynaptic assembly is not concurrent. Timecourse analysis shows that Wnt7a induces clustering of the presynaptic protein vesicular glutamate transporter1 (vGlut1) within $15 \mathrm{~min}$, whereas clustering of the postsynaptic scaffold protein PSD95 takes longer (Ciani et al., 2011). These results suggest that the presynaptic terminal responds faster to Wnt7a than the postsynaptic side. It is currently unclear whether Wnt7a acts through different receptors to trigger different signaling cascades to coordinate the assembly at both sides of the synapse.

\section{SYNAPTIC FUNCTION}

The initial stages of synaptic differentiation occur within the first few hours after the establishment of the axo-dendritic contact. However, the development of a nascent synapse into a functional synapse involves the recruitment of hundreds of proteins, morphological changes and establishment of functional electrophysiological properties (Zhang and Benson, 2001; Knott et al., 2006; Nagerl et al., 2007).

Wnt signaling participates in presynaptic function by promoting the formation of more SV recycling sites and increasing neurotransmitter release (Ahmad-Annuar et al., 2006; Cerpa et al., 2008; Varela-Nallar et al., 2009). In hippocampal neurons, the intracellular activation of the canonical-Wnt signaling by 
expression of Wnt signaling components or by bath application of Wnt3a or Wnt7a increases the frequency of spontaneous and mEPSCs by a divergent-canonical pathway that mobilizes calcium and is independent of transcription (Beaumont et al., 2007; Cerpa et al., 2008; Avila et al., 2010). Further analyses of SV cycling dynamics showed that Wnt7a specifically enhances SV exocytosis to facilitate neurotransmitter release (Cerpa et al., 2008). Importantly, electrophysiological studies in the cerebellum of Wnt7a; D vl1 mutant mice reveal defects in the frequency of mEPSCs, without apparent changes at the structure of active zones as determined by electron microscopy (Ahmad-Annuar et al., 2006). These results suggest that Wnt signaling may be required for neurotransmitter release. Consistent with this hypothesis, Dvl1 has been shown to bind directly to Synaptotagmin (Kishida et al., 2007), a key protein in neurotransmission. Dvll appears to regulate SV exo- and endocytosis in PC12 cells (Kishida et al., 2007). Together these studies demonstrate that Wnt signaling contributes to the assembly of functionally active presynaptic sites. However, the role of Wnt signaling in neurotransmitter release remains to be fully demonstrated.

On dendrites, Wnt7a increases the growth and maturation of spines manifested by increased size and PSD95 content (Ciani et al., 2011). In hippocampal neurons, Wnt7a increases spine size by almost $50 \%$ within 3 hrs, and by $65 \%$ within 16 hrs indicating a rapid and progressive spine growth. Consistent with an increased spine head size, Wnt7a signaling regulates synaptic strength as determined by defects in evoked excitatory postsynaptic currents (EPSCs) in Wnt7a; Dvl1 mutant mice. Postsynaptic activation of the Wnt pathway by expression of Dvl1 also stimulates spine growth, increases the amount of PSD95 within dendritic spines and the number of spines containing PSD95 (Ciani et al., 2011). Several findings demonstrate that Wnt7a through Dvl1 and CaMKII modulates spine growth and synaptic strength by rapidly activating CaMKII within dendritic spines (Ciani et al., 2011; Figure 2). Given the role of CaMKII in the structural and functional plasticity of synapses, these findings raise the interesting possibility that Wnt7a signaling participates in postsynaptic plasticity in the adult brain.

Wnt signaling also modulates inhibitory synapse formation and function (Figure 2). Wnt5a increases the insertion and clustering of $\mathrm{GABA}_{\mathrm{A}}$ receptors in cultured hippocampal neurons (Cuitino et al., 2010). Moreover, evoked recordings demonstrate that Wnt5a rapidly increases the amplitude of GABA-mediated currents without affecting the pair pulse index suggesting the Wnt5a might act postsynaptically. This postsynaptic effect is blocked by KN93 suggesting that $\mathrm{Ca} 2+/$ calmodulin dependent kinase (CaMKs) are involved (Cuitino et al., 2010). Although it remains to be determined whether Wnt5a is necessary for the postsynaptic function of inhibitory synapses, these results demonstrate that different Wnts can promote excitatory and/or inhibitory synapse function.

\section{NEURONAL ACTIVITY REGULATES WNT LEVELS AND FRIZZLED RECEPTOR TRAFFICKING}

A number of studies have shown that neuronal activity stimulates the expression and/or release of Wnts in the developing and mature nervous system (Yu and Malenka, 2003; Chen et al.,
2006; Wayman et al., 2006; Gogolla et al., 2009; Sahores et al., 2010). Depolarization of young hippocampal neurons stimulates Wnt release, which in turn regulates dendritogenesis (Yu and Malenka, 2003; Wayman et al., 2006). In cultured hippocampal neurons, activation of N-methyl-D-aspartate receptors (NMDARs) through tetanic stimulation induces Wnt3a release resulting in the activation of the canonical Wnt pathway (Chen et al., 2006). Wnt2 is also regulated by activity through a mechanism that requires NMDAR activation and cAMP response element-binding protein (CREB)-mediated transcription to promote dendritic arborization of cultured hippocampal neurons (Wayman et al., 2006). Moreover, in vivo studies show that environmental enrichment (EE) stimulates Wnt7a/b expression in the adult mouse hippocampus during the remodeling of mossy fiber terminals that contact CA3 dendrites. Importantly, blockade of endogenous Wnts by local microinjection of the Wnt antagonist Sfrpl suppresses activitydependent presynaptic remodeling and synaptogenesis in the CA3 region (Gogolla et al., 2009). Collectively, these studies demonstrate that neuronal activity promotes the expression and/or release of Wnt ligands to regulate dendritic development and adult synaptic remodeling.

Activity-dependent Wnt release induces $\mathrm{Fz}$ receptor surface localization, which in turn promotes synapse assembly (Figure 3). In cultured hippocampal neurons, Fz5, a receptor for Wnt7a, translocates to the cell surface and to synaptic sites following high frequency stimulation (HFS; Sahores et al., 2010), a protocol that induces long-term potentiation (LTP). Importantly, the Wnt antagonists Sfrps or the CRD of Fz5 that sequesters endogenous Wnts that bind to the Fz5 receptor, block the synaptic localization of Fz5 during HFS. These findings suggest that neuronal activity promotes the expression and/or release of Wnt factors, which

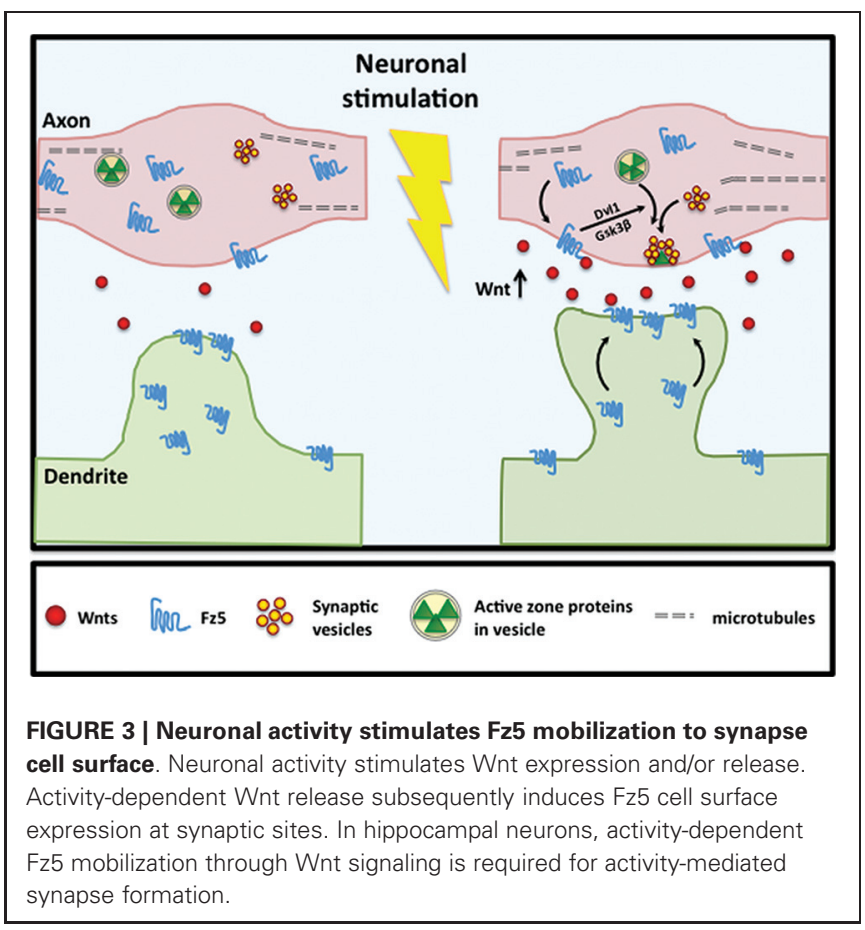


are required for Fz5 trafficking to the cell surface and to the synapse. Importantly, Wnt blockade also prevents HFS-mediated synapse assembly (Sahores et al., 2010). These findings demonstrate that Wnt-Fz5 signaling is required for activity-mediated synapse formation. It remains to be identified which Wnt isoforms are modulated by activity to promote Fz5 trafficking to the synapse.

\section{WNT SIGNALING AND FUNCTIONAL PLASTICITY OF MATURE SYNAPSES}

Synaptic plasticity refers to enduring changes in synaptic strength in response to different patterns of neuronal activity. Long-term changes to presynaptic neurotransmitter release and/or postsynaptic signal transduction through receptor availability and downstream effectors mediate synaptic plasticity. Synaptic plasticity mediates changes in sensory, motor and somatosensory inputs, as well as learning and memory. The patterns of expression of Wnts strongly suggest that they regulate these processes in the brain.

Wnts are released by activity-dependent mechanisms (Yu and Malenka, 2003; Chen et al., 2006; Wayman et al., 2006; Gogolla et al., 2009). Furthermore, Wnts and many of their signaling components continue to be expressed in the adult brain (Coyle-Rink et al., 2002; Shimogori et al., 2004; De Ferrari et al., 2007; Gogolla et al., 2009). Increasing evidence now suggests that sustained Wnt signaling may contribute to synaptic plasticity (Chen et al., 2006; Beaumont et al., 2007; Ataman et al., 2008; Cerpa et al., 2008; Gogolla et al., 2009; Varela-Nallar et al., 2010; Jensen et al., 2012). Enhanced sensory experience increases Wnt7a/b levels in the adult hippocampus, which act as retrograde signals inducing profound presynaptic plasticity-related modeling of CA3-CA1 mossy fiber synapses (Gogolla et al., 2009). Importantly, local application of the Wnt antagonist Sfrp1 by canulla injection during enhanced sensory experience prevents experience-dependent presynaptic remodeling and terminal complexity (Gogolla et al., 2009). Moreover, Wnt signaling acutely enhances the frequency and amplitude of spontaneous and evoked EPSCs in mature hippocampal neurons (Beaumont et al., 2007; Varela-Nallar et al., 2010; Ciani et al., 2011). These findings suggest that Wnts may contribute to activity-dependent plasticity. Indeed, a role for Wnt in LTP has been suggested. In acute hippocampal brain slices activation of the canonical-Wnt signaling by exogenous Wnt3a or lithium weakly facilitates LTP, whereas specific antibodies against Wnt3a or the secreted extracellular domain of Fz8 decreases LTP (Chen et al., 2006). More recently, Wnt5a has also been shown to facilitate LTP at CA3-CA1 synapses (Cerpa et al., 2011). These studies strongly suggest that Wnts modulate LTP. However, lossof-function studies are required to fully demonstrate whether Wnt signaling is required for LTP.

\section{WNT SIGNALING IN SYNAPTIC MAINTENANCE}

In vivo imaging demonstrates that $70-90 \%$ of synapses in the mature brain are stable and persist for extended periods of time, perhaps for the lifespan of the animal (Trachtenberg et al., 2002; Meyer et al., 2003; Alvarez and Sabatini, 2007; Bhatt et al., 2009; Holtmaat and Svoboda, 2009). Synaptic function and maintenance do not only determine stimulus transmission in the brain, but also the stability of axonal and dendritic arbors (Wu and Cline, 1998; Rajan et al., 1999; Niell et al., 2004; Hu et al., 2005; Meyer and Smith, 2006; Ruthazer et al., 2006; Chen et al., 2010). During development, motile "exploratory" axonal branches form preferentially at nascent presynaptic sites; in contrast stable presynaptic sites inhibit dynamic axon behaviors and growth, and are associated with stable axonal branches (Meyer and Smith, 2006). These studies are supported by the finding of a direct correlation between synaptic maintenance and local axon stability, which is enhanced by neuronal activity (Ruthazer et al., 2006). The relationship between synaptic and axonal maintenance is equally reflected in dendritic arbor structure, where loss of synapses is associated with dendritic retraction (Sfakianos et al., 2007; Lin and Koleske, 2010). Together, the findings suggest that axon and dendrite stability and the preservation of neuronal networks are determined by synaptic maintenance.

In contrast to stable synaptic structure, synaptic proteins are highly labile with half-lives of just days or even less (Huh and Wenthold, 1999; Ehlers, 2003). Synaptic proteins shuttle in and out of synapses at a remarkable rate through lateral diffusion or exo- and endocytosis (Malinow and Malenka, 2002; Bredt and Nicoll, 2003; Wenthold et al., 2003; Collingridge et al., 2004; Cognet et al., 2006; Gray et al., 2006; Ehlers et al., 2007; Kielland et al., 2009). Synaptic proteins such as Ras, Shank, PSD-95, Bassoon and Synaptophysin are redistributed between adjacent synapses over a time scale of minutes and hours (Kim and Sheng, 2004; Gray et al., 2006; Tsuriel et al., 2006, 2009). Furthermore, highly motile SVs are recycled between multiple presynaptic sites (Darcy et al., 2006; Staras et al., 2010). These studies raise a fundamental question; if synaptic components are only transiently located to synaptic sites, how is the long-term integrity of the synapse maintained?

Synaptogenic factors are ideally suited to modulate synaptic stability. Indeed, Wnt signaling has now been demonstrated to regulate synaptic maintenance in mature neurons. Time-lapse imaging experiments demonstrate that Wnt signaling blockade by

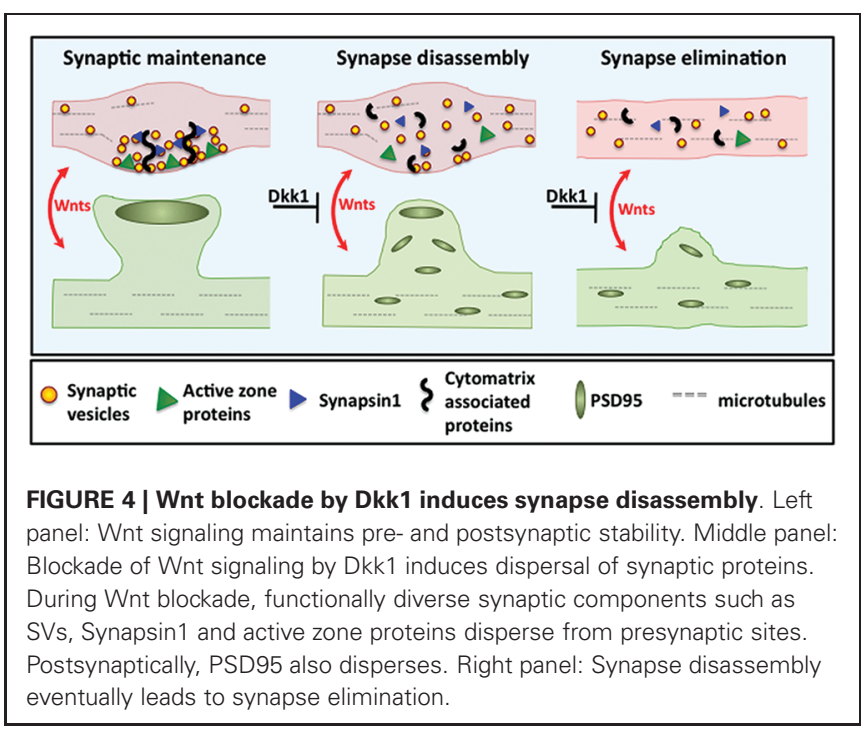


the secreted antagonist Dkk1 eliminates previously stable presynaptic sites within $20 \mathrm{~min}$ (Purro et al., 2012). Dkk1 rapidly induces the delocalization of pre- and postsynaptic components in mature and stable hippocampal synapses (Figure 4). This effect is accompanied by a reduced number of SV recycling sites. Importantly, ultrastructural analyses of remaining synapses reveal smaller active zones and postsynaptic densities, suggesting coordinated pre- and postsynaptic shrinkage and disassembly by Wnt blockade with Dkk1. These synaptic changes occur in the absence of cell death or decreased cell viability (Purro et al., 2012), suggesting that Dkk1 directly affects the synapse. These findings provide evidence that endogenous Wnt signaling is required for synaptic maintenance.

Synaptic activity is the key stimulus for maintaining the molecular composition of synapses. Several synaptic proteins and signaling molecules are synthesized in an activity dependent manner (Steward and Schuman, 2001; West et al., 2001). Activitydependent mechanisms also regulate the trafficking of synaptic proteins to active synaptic sites (Ehlers et al., 2007; Kielland et al., 2009). As discussed above, neuronal activity regulates the expression and release of Wnts. Moreover, Wnt blockade induces rapid synapse disassembly (Purro et al., 2012). We therefore propose that neuronal activity promotes the stability of synapses by modulating the levels of Wnts. Conversely, at inactive synapses limited levels of Wnts could render these synapses more prone to destabilization and disassembly.

Mounting evidence suggests that in several neurodegenerative diseases, the loss of synapses correlates well with cognitive decline and motor impairment before cell death is evident. These findings highlight the importance for understanding the cellular and molecular mechanisms that control the stability of synapses while permitting plastic changes to occur.

\section{DYSFUNCTIONAL WNT SIGNALING IN NEURODEGENERATIVE DISORDERS}

Dysfunctional Wnt signaling is linked to a number of neurological disorders including autism, schizophrenia, bipolar disorders, Alzheimer's disease (AD) and Parkinson's disease (De Ferrari and Moon, 2006; Inestrosa and Arenas, 2010; Okerlund and Cheyette, 2011; Scott et al., 2013). A common feature underlying these neurological disorders is aberrant synapse function and/or synapse degeneration. Synapse disassembly often precedes and might even trigger the widespread and catastrophic cell death that hallmarks many neurodegenerative disorders (Selkoe, 2002; Luo and O'Leary, 2005; Saxena and Caroni, 2007; Shankar et al., 2007; Stevens et al., 2007; Rosen and Stevens, 2010; Kessels et al., 2013). Biopsies of human $\mathrm{AD}$ brains reveal a $\sim 15-35 \%$ loss of synapses per neuron within 2-4 years of clinical AD onset (Terry et al., 1991). Importantly, the degree of cognitive decline correlates with loss of Synaptophysin-labeled presynaptic sites (Masliah et al., 2001). These findings are consistent with the results obtained from transgenic mouse models of $\mathrm{AD}$, where spine loss is best correlated with cognitive impairment than with the deposits of Amyloid plaques (Knobloch and Mansuy, 2008). Synapse loss in the $\mathrm{AD}$ brain correlates with the accumulation of soluble Amyloid- $\beta$ ( $A \beta$ ) prior to the onset of neuronal cell death, suggesting that soluble $\mathrm{A} \beta$ contributes to synaptic defects (Hsia et al., 1999; Selkoe, 2002; Lacor et al., 2007; Shankar et al., 2007). Indeed, $A ß$ modulates synaptic molecules resulting in synaptic dysfunction (Cisse et al., 2011). However, the molecular mechanisms by which soluble $\mathrm{A} \beta$ promotes synapse loss are poorly understood. Together the findings strongly suggest that synapse disassembly is an early event in $\mathrm{AD}$.

A potential role for Wnt signaling in the pathogenesis of $\mathrm{AD}$ has been suggested by a number of recent studies (De Ferrari and Moon, 2006; Caraci et al., 2008; Inestrosa and Arenas, 2010; Purro et al., 2012). Exogenous Wnt5a ameliorates A $\beta$-induced cell death in hippocampal neurons (De Ferrari et al., 2003; Cerpa et al., 2010). In addition, Wnt 3 a rescues $A \beta$-mediated loss of neurogenesis and neural differentiation in embryonic hippocampal progenitor cells in vitro (Shruster et al., 2011). Soluble A $\beta$ binds to Fz5 and blocks canonical Wnt signaling in NB2A cells (Magdesian et al., 2008). Increased Gsk3 $\beta$ activity, which inhibits Wnt signaling, induces the hyperphosphorylation of Tau and adversely affects Amyloid precursor protein (APP) processing (Mudher et al., 2001; Hooper et al., 2008). However, the first clear link between Wnt signaling and AD came from a genomewide association study demonstrating that a genetic variant of LRP6, the receptor for Dkk1, is strongly associated with lateonset AD (De Ferrari et al., 2007). This variant of LRP6 exhibits decreased level of Wnt signaling. Together these results suggest that decreased levels of Wnt signaling could contribute to $A \beta$ mediated neuropathogenesis.

Further links between dysfunction of Wnt signaling and AD comes from studies on the Wnt antagonist Dkk1. Dkk1 expression is elevated in human postmortem $\mathrm{AD}$ brains and in mouse models of AD (Caricasole et al., 2004; Rosi et al., 2010). In hippocampal brain slices, acute exposure to $A \beta$ oligomers rapidly increases Dkk1 mRNA and Dkk1 protein levels in the CA1, CA3 and DG (within $3 \mathrm{hrs),} \mathrm{with} \mathrm{a} \mathrm{concomitant} \mathrm{loss} \mathrm{of} \mathrm{synapses}$ (Purro et al., 2012). Crucially, blockade of Dkk1 with specific neutralizing antibodies suppresses the ability of $A \beta$ to stimulate synapse loss (Purro et al., 2012). These studies demonstrate that $D k k 1$ is required for $A \beta$-induced synapse elimination. We propose that dysfunction in Wnt signaling contributes to Aß-mediated synaptic toxicity and the subsequence cognitive decline observed in dementia (Figure 5).

How does $A \beta$ induce Dkk1 expression? A recent report suggests that increased soluble $A \beta$ induces the intracellular accumulation of the cell survival factor clusterin, possibly by preventing its neural secretion (Killick et al., 2012). It was posited that intracellular clusterin accumulation activates p 53 signaling, which stimulates Dkk1 expression. Consistent with this idea, knockdown of clusterin prevents $A \beta$ toxicity and upregulation of Dkk1 in cultured hippocampal neurons. Moreover, pharmacological inhibition of the p53 pathway blocks $A \beta$ induction of Dkk1 (Killick et al., 2012). Thus, p53 activation contributes to A $\beta$ mediated Dkk1 induction. It would be critical to establish whether p53 also contributes to Dkk1 increased levels during synaptic disassembly induced by $\mathrm{A} \beta$ in vivo.

Recent studies have shown that endogenous Dkk1 expression becomes progressively elevated in the aged brain and may be associated with general cognitive decline as well as susceptibility 


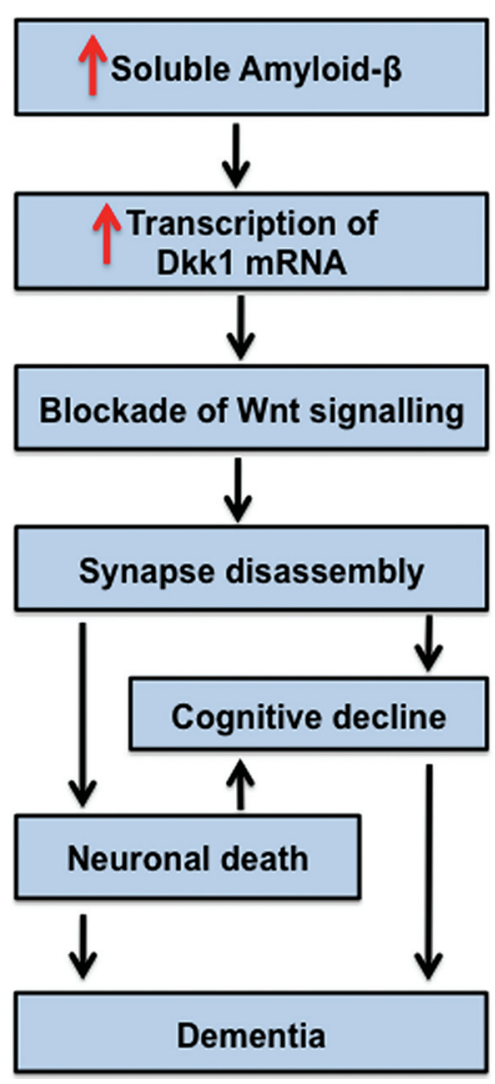

FIGURE 5 | Model for Dkk1 in the progression of AD. Increased levels of soluble Amyloid- $\beta$ stimulate the transcription of Dkk1, which blocks endogenous Wnts important to the stability of synapses. Thus, Dkk1 induces synapse disassembly by the dispersal of synaptic components. Loss of synapses correlates with cognitive decline. We propose that Dkk1-induced synapse elimination is an early event in the progression of $\mathrm{AD}$. The notion that synapse disassembly precedes cell death is in accordance with current models for the progression of $A D$.

to age related pathological neurodegenerative disorder (Scott et al., 2013; Seib et al., 2013). Indeed, Dkk1 knockdown increases neurogenesis in the adult hippocampus and this effect has been

\section{REFERENCES}

Ahmad-Annuar, A., Ciani, L., Simeonidis, I., Herreros, J., Fredj, N. B., Rosso, S. B., et al. (2006). Signaling across the synapse: a role for Wnt and Dishevelled in presynaptic assembly and neurotransmitter release. J. Cell Biol. 174, 127-139. doi: 10.1083/jcb.200511054

Alvarez, V. A., and Sabatini, B. L. (2007). Anatomical and physiological plasticity of dendritic spines. Annu. Rev. Neurosci. 30, 79-97. doi: 10.1146/annurev.neuro. 30.051606 .094222

Angers, S., and Moon, R. T. (2009). Proximal events in Wnt signal transduction. Nat. Rev. Mol. Cell Biol. 10, 468-477. doi: 10.1038/ nrm 2717
Ataman, B., Ashley, J., Gorczyca, M., Ramachandran, P., Fouquet, W., Sigrist, S. J., et al. (2008). Rapid activity-dependent modifications in synaptic structure and function Neuron 57, 705-718. doi: 10.1016/j. neuron.2008.01.026 gos, C. F., Moraga-Cid, G., Parodi, J., Moon, R. T., et al. (2010). Canonical Wnt3a modulates intracellular calcium and enhances excitatory neurotransmission in hippocampal neurons. J. Biol. Chem. 285, 18939-18947. doi: 10.1074/jbc. m110.103028

Beaumont, V., Thompson, S. A., Choudhry, F., Nuthall, H., Glantschnig, H., Lipfert, L., require bidirectional Wnt signaling.

Avila, M. E., Sepulveda, F. J., Bur-

correlated with enhanced working spatial memory and memory consolidation (Seib et al., 2013). However, it remains to be examined whether changes in spatial memory are due to changes in synapse integrity.

\section{CONCLUDING REMARKS}

The delicate balance between synapse assembly, disassembly and maintenance are highly regulated processes controlled by a complex molecular dialogue between pre- and postsynaptic neurons. Importantly, neuronal activity, which has profound effects on these processes, contributes to the expression and release of Wnt factors, which in turn modulate this trans-synaptic dialogue. Indeed, several studies have demonstrated that Wnts contribute to activity-mediated synapse formation during early neuronal circuit development and during experience-dependent plasticity.

Wnt-mediated synaptic maintenance is now emerging in relation to neurodegeneration. Indeed, the Wnt antagonist Dkk1, which has strong synaptic disassembly activity, is now linked to $A D$. Importantly, Dkk1 mediates the effect of $A \beta$ on synaptic disassembly. Future in vivo studies will provide key evidence for the contribution of dysfunction in Wnt signaling to synaptic degeneration in $\mathrm{AD}$.

It is an exciting time to study Wnt signaling in the nervous system as we begin to unravel the mechanisms by which Wnts modulate experience-mediated plasticity. Moreover, the potential role of Wnts in synaptic maintenance opens new avenues to develop therapeutic strategies for the treatment of neurodegenerative diseases at early stages. Finally, the finding that Dkk1 is elevated in the $\mathrm{AD}$ brain has sparked enthusiasm that this molecule could be used as a biomarker at early stages of $\mathrm{AD}$ or other neurodegenerative diseases.

\section{ACKNOWLEDGMENTS}

We thank members of our laboratory for useful discussion and comments on the manuscript. The MRC, BBSRC ( $\mathrm{PhD}$ studentship to EMD), ARUK, The Wellcome Trust, Parkinson's UK and European Union (MOLPARK) supported our work.

et al. (2007). Evidence for an enhancement of excitatory transmission in adult CNS by Wnt signaling pathway modulation. Mol. Cell. Neurosci. 35, 513-524. doi: 10.1016/j.mcn.2007. 03.004

Bhatt, D. H., Zhang, S., and Gan, W. B. (2009). Dendritic spine dynamics. Annu. Rev. Physiol. 71, 261282. doi: 10.1146/annurev.physiol. 010908.163140

Bredt, D. S., and Nicoll, R. A. (2003). AMPA receptor trafficking at excitatory synapses. Neuron 40, 361379. doi: 10.1016/s0896-6273(03) 00640-8

Budnik, V., and Salinas, P. C. (2011). Wnt signaling during synaptic development and plasticity. Curr.
Opin. Neurobiol. 21, 151-159. doi: 10.1016/j.conb.2010.12.002

Caraci, F., Busceti, C., Biagioni, F., Aronica, E., Mastroiacovo, F., Cappuccio, I., et al. (2008). The Wnt antagonist, Dickkopf1 , as a target for the treatment of neurodegenerative disorders. Neurochem. Res. 33, 24012406. doi: 10.1007/s11064-0089710-0

Caricasole, A., Copani, A., Caraci, F., Aronica, E., Rozemuller, A. J., Caruso, A., et al. (2004). Induction of Dickkopf-1, a negative modulator of the Wnt pathway, is associated with neuronal degeneration in Alzheimer's brain. J. Neurosci. 24, 6021-6027. doi: 10.1523/jneurosci. 1381-04.2004 
Cerpa, W., Farias, G. G., Godoy, J. A., Fuenzalida, M., Bonansco, C., and Inestrosa, N. C. (2010). Wnt-5a occludes Abeta oligomerinduced depression of glutamatergic transmission in hippocampal neurons. Mol. Neurodegener. 5:3. doi: 10. 1186/1750-1326-5-3

Cerpa, W., Gambrill, A., Inestrosa, N. C., and Barria, A. (2011). Regulation of NMDA-receptor synaptic transmission by Wnt signaling. $J$. Neurosci. 31, 9466-9471. doi: 10. 1523/JNEUROSCI.6311-10.201

Cerpa, W., Godoy, J. A., Alfaro, I., Farias, G. G., Metcalfe, M. J., Fuentealba, R., et al. (2008). Wnt-7a modulates the synaptic vesicle cycle and synaptic transmission in hippocampal neurons. J. Biol. Chem. 283, 5918-5927. doi: 10.1074/jbc. m705943200

Chen, J., Park, C. S., and Tang, S. J. (2006). Activity-dependent synaptic Wnt release regulates hippocampal long term potentiation. J. Biol. Chem. 281, 11910-11916. doi: 10. 1074/jbc.m511920200

Chen, S. X., Tari, P. K., She, K., and Haas, K. (2010). Neurexinneuroligin cell adhesion complexes contribute to synaptotropic dendritogenesis via growth stabilization mechanisms in vivo. Neuron 67, 967-983. doi: 10.1016/j.neuron. 2010.08.016

Ciani, L., Boyle, K. A., Dickins, E., Sahores, M., Anane, D., Lopes, D. M., et al. (2011). Wnt7a signaling promotes dendritic spine growth and synaptic strength through $\mathrm{Ca}(2) / C a l m o d u l i n-d e p e n d e n t$ protein kinase II. Proc. Natl. Acad. Sci. U S A 108, 10732-10737. doi: 10. 1073/pnas.1018132108

Ciani, L., Krylova, O., Smalley, M. J., Dale, T. C., and Salinas, P. C. (2004). A divergent canonical WNT-signaling pathway regulates microtubule dynamics: dishevelled signals locally to stabilize microtubules. J. Cell Biol. 164, 243-253. doi: 10.1083/jcb.200309096

Ciani, L., and Salinas, P. C. (2005). WNTs in the vertebrate nervous system: from patterning to neuronal connectivity. Nat. Rev. Neurosci. 6, 351-362. doi: 10.1038/nrn1665

Cisse, M., Halabisky, B., Harris, J., Devidze, N., Dubal, D. B., Sun, B., et al. (2011). Reversing EphB2 depletion rescues cognitive functions in Alzheimer model. Nature 469, 4752. doi: $10.1038 /$ nature 09635

Cognet, L., Groc, L., Lounis, B., and Choquet, D. (2006). Multiple routes for glutamate receptor trafficking: surface diffusion and membrane traffic cooperate to bring receptors to synapses. Sci. STKE 2006, pe13. doi: 10.1126/stke.3272006pe13

Collingridge, G. L., Isaac, J. T., and Wang, Y. T. (2004). Receptor trafficking and synaptic plasticity. Nat. Rev. Neurosci. 5, 952-962. doi: 10. 1038/nrn1556

Coyle-Rink, J., Del Valle, L., Sweet, T., Khalili, K., and Amini, S. (2002). Developmental expression of Wnt signaling factors in mouse brain. Cancer Biol. Ther. 1, 640-645.

Cuitino, L., Godoy, J. A., Farias, G. G., Couve, A., Bonansco, C., Fuenzalida, M., et al. (2010). Wnt-5a modulates recycling of functional GABAA receptors on hippocampal neurons. J. Neurosci. 30, 8411-8420. doi: 10.1523/JNEUROSCI.5736-09. 2010

Darcy, K. J., Staras, K., Collinson, L. M., and Goda, Y. (2006). Constitutive sharing of recycling synaptic vesicles between presynaptic boutons. Nat. Neurosci. 9, 315-321. doi: 10. 1038/nn1640

Davis, E. K., Zou, Y., and Ghosh, A. (2008). Wnts acting through canonical and noncanonical signaling pathways exert opposite effects on hippocampal synapse formation. Neural Dev. 3:32. doi: 10.1186/17498104-3-32

De Ferrari, G. V., Chacon, M. A., Barria, M. I., Garrido, J. L., Godoy, J. A., Olivares, G., et al. (2003). Activation of Wnt signaling rescues neurodegeneration and behavioral impairments induced by beta-amyloid fibrils. Mol. Psychiatry 8, 195-208. doi: 10.1038/sj.mp.4001208

De Ferrari, G. V., and Moon, R. T. (2006). The ups and downs of Wnt signaling in prevalent neurological disorders. Oncogene 25, 7545-7553. doi: 10.1038/sj.onc.1210064

De Ferrari, G. V., Papassotiropoulos, A., Biechele, T., Wavrant De-Vrieze, F., Avila, M. E., Major, M. B., et al. (2007). Common genetic variation within the low-density lipoprotein receptor-related protein 6 and late-onset Alzheimer's disease. Proc. Natl. Acad. Sci. U S A 104, 94349439. doi: $10.1073 /$ pnas. 0603523104 Ehlers, M. D. (2003). Activity level controls postsynaptic composition and signaling via the ubiquitinproteasome system. Nat. Neurosci. 6, 231-242. doi: 10.1038/nn1013

Ehlers, M. D., Heine, M., Groc, L., Lee, M. C., and Choquet, D. (2007). Diffusional trapping of GluR1 AMPA receptors by input-specific synaptic activity. Neuron 54, 447-460. doi: 10.1016/j.neuron.2007.04.010
Farias, G. G., Alfaro, I. E., Cerpa, W., Grabowski, C. P., Godoy, J. A., Bonansco, C., et al. (2009). Wnt-5a/JNK signaling promotes the clustering of PSD-95 in hippocampal neurons. J. Biol. Chem. 284, 15857-15866. doi: 10.1074/jbc. m808986200

Galjart, N. (2005). CLIPs and CLASPs and cellular dynamics. Nat. Rev. Mol. Cell Biol. 6, 487-498. doi: 10. 1038/nrm1664

Gogolla, N., Galimberti, I., Deguchi, Y., and Caroni, P. (2009). Wnt signaling mediates experience-related regulation of synapse numbers and mossy fiber connectivities in the adult hippocampus. Neuron 62, 510-525. doi: 10.1016/j.neuron.2009.04.022

Gordon, M. D., and Nusse, R. (2006). Wnt signaling: multiple pathways, multiple receptors, and multiple transcription factors. J. Biol. Chem. 281, 22429-22433. doi: 10.1074/jbc. r600015200

Gray, N. W., Weimer, R. M., Bureau, I., and Svoboda, K. (2006). Rapid redistribution of synaptic PSD-95 in the neocortex in vivo. PLoS Biol. 4:e370. doi: 10.1371/journal.pbio. 0040370

Hall, A. C., Lucas, F. R., and Salinas, P. C. (2000). Axonal remodeling and synaptic differentiation in the cerebellum is regulated by WNT-7a signaling. Cell 100, 525-535. doi: 10 . 1016/s0092-8674(00)80689-3

Henriquez, J. P., Webb, A., Bence, M., Bildsoe, H., Sahores, M., Hughes, S. M., et al. (2008). Wnt signaling promotes AChR aggregation at the neuromuscular synapse in collaboration with agrin. Proc. Natl. Acad. Sci. US A 105, 18812-18817. doi: 10. 1073/pnas.0806300105

Holtmaat, A., and Svoboda, K. (2009). Experience-dependent structural synaptic plasticity in the mammalian brain. Nat. Rev. Neurosci. 10, 647-658. doi: 10.1038/nrn2699

Hooper, C., Killick, R., and Lovestone, S. (2008). The GSK3 hypothesis of Alzheimer's disease. J. Neurochem. 104, 1433-1439. doi: 10. 1111/j.1471-4159.2007.05194.x

Hsia, A. Y., Masliah, E., McConlogue, L., Yu, G. Q., Tatsuno, G., Hu, K. et al. (1999). Plaque-independent disruption of neural circuits in Alzheimer's disease mouse models. Proc. Natl. Acad. Sci. U S A 96, 32283233. doi: $10.1073 /$ pnas. 96.6 .3228

Hu, B., Nikolakopoulou, A. M., and Cohen-Cory, S. (2005). BDNF stabilizes synapses and maintains the structural complexity of optic axons in vivo. Development 132, 4285 4298. doi: 10.1242/dev.02017
Huh, K. H., and Wenthold, R. J. (1999). Turnover analysis of glutamate receptors identifies a rapidly degraded pool of the N-methyl-Daspartate receptor subunit, NR1, in cultured cerebellar granule cells. J. Biol. Chem. 274, 151-157. doi: 10. 1074/jbc.274.1.151

Ille, F., and Sommer, L. (2005). Wnt signaling: multiple functions in neural development. Cell Mol. Life Sci. 62, 1100-1108. doi: 10.1007/s00018005-4552-2

Inestrosa, N. C., and Arenas, E. (2010). Emerging roles of Wnts in the adult nervous system. Nat. Rev. Neurosci. 11, 77-86. doi: 10.1038/nrn2755

Jensen, M., Hoerndli, F. J., Brockie, P. J., Wang, R., Johnson, E., Maxfield, D., et al. (2012). Wnt signaling regulates acetylcholine receptor translocation and synaptic plasticity in the adult nervous system. Cell 149, 173-187. doi: 10.1016/j.cell.2011.12.038

Kessels, H. W., Nabavi, S., and Malinow, R. (2013). Metabotropic NMDA receptor function is required for beta-amyloid-induced synaptic depression. Proc. Natl. Acad. Sci. U S A 110, 4033-4038. doi: 10. 1073/pnas.1219605110

Kielland, A., Bochorishvili, G., Corson, J., Zhang, L., Rosin, D. L., Heggelund, P., et al. (2009). Activity patterns govern synapse-specific AMPA receptor trafficking between deliverable and synaptic pools. $\mathrm{Neu}$ ron 62, 84-101. doi: 10.1016/j. neuron.2009.03.001

Kikuchi, A., Yamamoto, H., and Kishida, S. (2007). Multiplicity of the interactions of Wnt proteins and their receptors. Cell. Signal. 19, 659-671. doi: 10.1016/j.cellsig.2006. 11.001

Killick, R., Ribe, E. M., Al-Shawi, R., Malik, B., Hooper, C., Fernandes, C., et al. (2012). Clusterin regulates beta-amyloid toxicity via Dickkopf-1-driven induction of the wnt-PCP-JNK pathway. Mol. Psychiatry doi: 10.1038/mp.2012.163. [Epub ahead of print].

Kim, E., and Sheng, M. (2004). PDZ domain proteins of synapses. Nat. Rev. Neurosci. 5, 771-781. doi: 10. 1038/nrn1517

Kishida, S., Hamao, K., Inoue, M., Hasegawa, M., Matsuura, Y., Mikoshiba, K., et al. (2007). Dvl regulates endo- and exocytotic processes through binding to synaptotagmin. Genes Cells 12, 49-61. doi: $\quad 10.1111 /$ j.1365-2443.2006. 01030.x

Knobloch, M., and Mansuy, I. M. (2008). Dendritic spine loss and synaptic alterations in Alzheimer's 
disease. Mol. Neurobiol. 37, 73-82. doi: 10.1007/s12035-008-8018-Z

Knott, G. W., Holtmaat, A., Wilbrecht, L., Welker, E., and Svoboda, K. (2006). Spine growth precedes synapse formation in the adult neocortex in vivo. Nat. Neurosci. 9, 1117-1124. doi: 10.1038/nn1747

Kohn, A. D., and Moon, R. T. (2005). Wnt and calcium signaling: betacatenin-independent pathways. Cell Calcium 38, 439-446. doi: 10.1016/j. ceca.2005.06.022

Krylova, O., Herreros, J., Cleverley, K. E., Ehler, E., Henriquez, J. P., Hughes, S. M., et al. (2002). WNT-3, expressed by motoneurons, regulates terminal arborization of neurotrophin-3-responsive spinal sensory neurons. Neuron 35, 1043-1056. doi: 10.1016/s08966273(02)00860-7

Lacor, P. N., Buniel, M. C., Furlow, P. W., Clemente, A. S., Velasco, P. T., Wood, M., et al. (2007). Abeta oligomer-induced aberrations in synapse composition, shape, and density provide a molecular basis for loss of connectivity in Alzheimer's disease. J. Neurosci. 27, 796-807. doi: 10.1523/jneurosci. 3501-06.2007

Lin, Y. C., and Koleske, A. J. (2010). Mechanisms of synapse and dendrite maintenance and their disruption in psychiatric and neurodegenerative disorders. Annu. Rev. Neurosci. 33, 349-378. doi: 10. 1146/annurev-neuro-060909153204

Logan, C. Y., and Nusse, R. (2004). The Wnt signaling pathway in development and disease. Annu. Rev. Cell Dev. Biol. 20, 781-810. doi: 10.1146/annurev.cellbio.20. 010403.113126

Lucas, F. R., Goold, R. G., GordonWeeks, P. R., and Salinas, P. C. (1998). Inhibition of GSK-3beta leading to the loss of phosphorylated MAP-1B is an early event in axonal remodelling induced by WNT-7a or lithium. J. Cell Sci. 111 (Pt 10), 1351-1361.

Lucas, F. R., and Salinas, P. C. (1997). WNT-7a induces axonal remodeling and increases synapsin I levels in cerebellar neurons. Dev. Biol. 192, 31-44. doi: 10.1006/dbio.1997.8734

Luo, L., and O'Leary, D. D. (2005). Axon retraction and degeneration in development and disease. Annu. Rev. Neurosci. 28, 127-156. doi: 10. 1146/annurev.neuro.28.061604. 135632

Magdesian, M. H., Carvalho, M. M., Mendes, F. A., Saraiva, L. M., Juliano, M. A., Juliano, L., et al.
(2008). Amyloid-beta binds to the extracellular cysteine-rich domain of Frizzled and inhibits Wnt/betacatenin signaling. J. Biol. Chem. 283, 9359-9368. doi: 10.1074/jbc. m707108200

Malinow, R., and Malenka, R. C. (2002). AMPA receptor trafficking and synaptic plasticity. Annu. Rev. Neurosci. 25, 103-126. doi: 10. 1146/annurev.neuro.25.112701. 142758

Masliah, E., Mallory, M., Alford, M., DeTeresa, R., Hansen, L. A., McKeel, D. W., Jr., and et al. (2001). Altered expression of synaptic proteins occurs early during progression of Alzheimer's disease. Neurology 56, 127-129. doi: 10.1212/wnl. 56.1.127

Meyer, M. P., Niell, C. M., and Smith, S. J. (2003). Brain imaging: how stable are synaptic connections? Curr. Biol. 13, R180-R182. doi: 10.1016/s09609822(03)00118-0

Meyer, M. P., and Smith, S. J. (2006). Evidence from in vivo imaging that synaptogenesis guides the growth and branching of axonal arbors by two distinct mechanisms. J. Neurosci. 26, 3604-3614. doi: 10. 1523/jneurosci.0223-06.2006

Mikels, A. J., and Nusse, R. (2006). Purified Wnt5a protein activates or inhibits beta-catenin-TCF signaling depending on receptor context. PLoS Biol. 4:e115. doi: 10. 1371/journal.pbio.0040115

Mudher, A., Chapman, S., Richardson, J., Asuni, A., Gibb, G., Pollard, C., et al. (2001). Dishevelled regulates the metabolism of amyloid precursor protein via protein kinase $\mathrm{C} /$ mitogen-activated protein kinase and c-Jun terminal kinase. J. Neurosci. 21, 4987-4995.

Nagerl, U. V., Kostinger, G., Anderson, J. C., Martin, K. A., and Bonhoeffer, T. (2007). Protracted synaptogenesis after activity-dependent spinogenesis in hippocampal neurons. $J$. Neurosci. 27, 8149-8156. doi: 10. 1523/jneurosci.0511-07.2007

Niell, C. M., Meyer, M. P., and Smith, S. J. (2004). In vivo imaging of synapse formation on a growing dendritic arbor. Nat. Neurosci. 7, 254-260. doi: 10.1038/nn1191

Okerlund, N. D., and Cheyette, B. N. (2011). Synaptic Wnt signalinga contributor to major psychiatric disorders? J. Neurodev. Disord. 3, 162-174. doi: 10.1007/s11689-0119083-6

Packard, M., Koo, E. S., Gorczyca, M., Sharpe, J., Cumberledge, S., and Budnik, V. (2002). The Drosophila Wnt, wingless, provides an essen- tial signal for pre- and postsynaptic differentiation. Cell 111, 319330. doi: 10.1016/s0092-8674(02) 01047-4

Paganoni, S., Bernstein, J., and Ferreira, A. (2010). Ror1-Ror2 complexes modulate synapse formation in hippocampal neurons. Neuroscience 165, 1261-1274. doi: 10 . 1016/j.neuroscience.2009.11.056

Park, M., and Shen, K. (2012). WNTs in synapse formation and neuronal circuitry. Embo J. 31, 2697-2704. doi: 10.1038/emboj.2012.145

Purro, S. A., Ciani, L., Hoyos-Flight, M., Stamatakou, E., Siomou, E., and Salinas, P. C. (2008). Wnt regulates axon behavior through changes in microtubule growth directionality: a new role for adenomatous polyposis coli. J. Neurosci. 28, 8644 8654. doi: 10.1523/jneurosci.232008.2008

Purro, S. A., Dickins, E. M., and Salinas, P. C. (2012). The secreted Wnt antagonist Dickkopf-1 is required for amyloid beta-mediated synaptic loss. J. Neurosci. 32, $3492-$ 3498. doi: 10.1523/jneurosci.456211.2012

Rajan, I., Witte, S., and Cline, H. T. (1999). NMDA receptor activity stabilizes presynaptic retinotectal axons and postsynaptic optic tectal cell dendrites in vivo. J. Neurobiol. 38, 357-368. doi: 10. 1002/(sici)1097-4695(19990215)38: $3<357$ ::aid-neu5>3.0.co;2-\#

Rosen, A. M., and Stevens, B. (2010). The role of the classical complement cascade in synapse loss during development and glaucoma. $A d v$. Exp. Med. Biol. 703, 75-93. doi: 10. 1007/978-1-4419-5635-4_6

Rosi, M. C., Luccarini, I., Grossi, C., Fiorentini, A., Spillantini, M. G., Prisco, A., et al. (2010). Increased Dickkopf-1 expression in transgenic mouse models of neurodegenerative disease. J. Neurochem. 112, 1539 1551. doi: 10.1111/j.1471-4159. 2009.06566.x

Rosso, S. B., Sussman, D., WynshawBoris, A., and Salinas, P. C. (2005). Wnt signaling through Dishevelled, $\mathrm{Rac}$ and JNK regulates dendritic development. Nat. Neurosci. 8, 34 42. doi: 10.1038/nn1374

Ruthazer, E. S., Li, J., and Cline, H. T. (2006). Stabilization of axon branch dynamics by synaptic maturation. J. Neurosci. 26, 3594-3603. doi: 10.1523/jneurosci.0069-06. 2006

Sahores, M., Gibb, A., and Salinas, P. C. (2010). Frizzled-5, a receptor for the synaptic organizer Wnt7a, regulates activity-mediated synaptoge- nesis. Development 137, 2215-2225. doi: 10.1242/dev.046722

Salinas, P. C. (2007). Modulation of the microtubule cytoskeleton: a role for a divergent canonical Wnt pathway. Trends Cell Biol. 17, 333-342. doi: 10.1016/j.tcb.2007. 07.003

Salinas, P. C. (2012). Wnt signaling in the vertebrate central nervous system: from axon guidance to synaptic function. Cold Spring Harb. Perspect. Biol. 4:a008003. doi: 10. 1101/cshperspect.a008003

Salinas, P. C., and Zou, Y. (2008). Wnt signaling in neural circuit assembly. Annu. Rev. Neurosci. 31, 339358. doi: 10.1146/annurev.neuro.31. 060407.125649

Saxena, S., and Caroni, P. (2007). Mechanisms of axon degeneration: from development to disease. Prog. Neurobiol. 83, 174-191. doi: 10. 1016/j.pneurobio.2007.07.007

Scott, E. L., and Brann, D. W. (2013). Estrogen regulation of Dkk1 and Wnt/beta-Catenin signaling in neurodegenerative disease. Brain Res. 1514, 63-74. doi: 10.1016/j.brainres. 2012.12.015

Scott, E. L., Zhang, Q. G., Han, D., Desai, B. N., and Brann, D. W. (2013). Long-term estrogen deprivation leads to elevation of Dickkopf-1 and dysregulation of Wnt/beta-Catenin signaling in hippocampal CA1 neurons. Steroids 78, 624-632. doi: 10.1016/j.steroids. 2012.11.004

Seib, D. R., Corsini, N. S., Ellwanger, K., Plaas, C., Mateos, A., Pitzer, C., et al. (2013). Loss of Dickkopf1 restores neurogenesis in old age and counteracts cognitive decline. Cell Stem Cell 12, 204-214. doi: 10. 1016/j.stem.2012.11.010

Selkoe, D. J. (2002). Alzheimer's disease is a synaptic failure. Science 298, 789-791. doi: 10.1126/science. 1074069

Sfakianos, M. K., Eisman, A., Gourley, S. L., Bradley, W. D., Scheetz, A. J., Settleman, J., et al. (2007). Inhibition of Rho via Arg and p190RhoGAP in the postnatal mouse hippocampus regulates dendritic spine maturation, synapse and dendrite stability, and behavior. $J$. Neurosci. 27, 10982-10992. doi: 10. 1523/jneurosci.0793-07.2007

Shankar, G. M., Bloodgood, B. L., Townsend, M., Walsh, D. M., Selkoe, D. J., and Sabatini, B. L. (2007). Natural oligomers of the Alzheimer amyloid-beta protein induce reversible synapse loss by modulating an NMDA-type glutamate receptor-dependent signaling 
pathway. J. Neurosci. 27, 2866-2875. doi: 10.1523/jneurosci.4970-06. 2007

Shimogori, T., VanSant, J., Paik, E., and Grove, E. A. (2004). Members of the Wnt, Fz, and Frp gene families expressed in postnatal mouse cerebral cortex. J. Comp. Neurol. 473, 496-510. doi: 10.1002/cne.20135

Shruster, A., Eldar-Finkelman, H., Melaned, E., and Offen, D. (2011). Wnt signaling pahtway overcomes the disruption of neuronal differentiation of neuronal progenitor cells induced by oligomeric amyloid beta-peptide. J. Neurochem. 116, 522-529. doi: 10.1111/j.1471-4159. 2010.07131.x

Staras, K., Branco, T., Burden, J. J., Pozo, K., Darcy, K., Marra, V., et al. (2010). A vesicle superpool spans multiple presynaptic terminals in hippocampal neurons. Neuron 66, 37-44. doi: 10.1016/j.neuron.2010. 03.020

Stevens, B., Allen, N. J., Vazquez, L. E., Howell, G. R., Christopherson, K. S., Nouri, N., et al. (2007). The classical complement cascade mediates CNS synapse elimination. Cell 131, 1164 1178. doi: 10.1016/j.cell.2007.10.036

Steward, O., and Schuman, E. M. (2001). Protein synthesis at synaptic sites on dendrites. Annu. Rev. Neurosci. 24, 299-325. doi: 10. 1146/annurev.neuro.24.1.299

Terry, R. D., Masliah, E., Salmon, D. P., Butters, N., DeTeresa, R., Hill,
R., et al. (1991). Physical basis of cognitive alterations in Alzheimer's disease: synapse loss is the major correlate of cognitive impairment. Ann. Neurol. 30, 572-580. doi: 10. 1002/ana.410300410

Trachtenberg, J. T., Chen, B. E., Knott, G. W., Feng, G., Sanes, J. R., Welker, E., et al. (2002). Long-term in vivo imaging of experience-dependent synaptic plasticity in adult cortex. Nature 420, 788-794. doi: 10. 1038/nature 01273

Tsuriel, S., Fisher, A., Wittenmayer, N., Dresbach, T., Garner, C. C., and Ziv, N. E. (2009). Exchange and redistribution dynamics of the cytoskeleton of the active zone molecule bassoon. J. Neurosci. 29, 351-358. doi: 10.1523/JNEUROSCI.4777-08. 2009

Tsuriel, S., Geva, R., Zamorano, P., Dresbach, T., Boeckers, T., Gundelfinger, E. D., et al. (2006). Local sharing as a predominant determinant of synaptic matrix molecular dynamics. PLoS Biol. 4:e271. doi: 10. 1371/journal.pbio.0040271

van Amerongen, R., and Nusse, R. (2009). Towards an integrated view of Wnt signaling in development. Development 136, 3205-3214. doi: 10.1242/dev.033910

Varela-Nallar, L., Alfaro, I. E., Serrano, F. G., Parodi, J., and Inestrosa, N. C. (2010). Wingless-type family member 5A (Wnt-5a) stimulates synaptic differentiation and function of glutamatergic synapses. Proc. Natl. Acad. Sci. U S A 107, 21164-21169. doi: 10.1073/pnas.1010011107

Varela-Nallar, L., Grabowski, C. P., Alfaro, I. E., Alvarez, A. R., and Inestrosa, N. C. (2009). Role of the Wnt receptor Frizzled-1 in presynaptic differentiation and function. Neural Dev. 4:41. doi: 10.1186/17498104-4-41

Wayman, G. A., Impey, S., Marks, D., Saneyoshi, T., Grant, W. F., Derkach, V., et al. (2006). Activity-dependent dendritic arborization mediated by CaM-kinase I activation and enhanced CREB-dependent transcription of Wnt-2. Neuron 50, 897-909. doi: 10.1016/j.neuron. 2006.05.008

Wenthold, R. J., Prybylowski, K., Standley, S., Sans, N., and Petralia, R. S. (2003). Trafficking of NMDA receptors. Annu. Rev. Pharmacol. Toxicol. 43, 335-358.

West, A. E., Chen, W. G., Dalva, M. B., Dolmetsch, R. E., Kornhauser, J. M. Shaywitz, A. J., et al. (2001). Calcium regulation of neuronal gene expression. Proc. Natl. Acad. Sci. U S A 98, 11024-11031. doi: 10 . 1073/pnas. 191352298

Wu, G. Y., and Cline, H. T. (1998). Stabilization of dendritic arbor structure in vivo by CaMKII. Science 279, 222-226. doi: 10.1126/science.279. 5348.222

Yu, X., and Malenka, R. C. (2003). Betacatenin is critical for dendritic mor- phogenesis. Nat. Neurosci. 6, 1169 1177. doi: 10.1038/nn1132

Zhang, W., and Benson, D. L. (2001) Stages of synapse development defined by dependence on F-actin. J. Neurosci. 21, 5169-5181.

Conflict of Interest Statement: The authors declare that the research was conducted in the absence of any commercial or financial relationships that could be construed as a potential conflict of interest.

Received: 25 June 2013; accepted: 04 September 2013; published online: 05 November 2013.

Citation: Dickins EM and Salinas PC (2013) Wnts in action: from synapse formation to synaptic maintenance. Front. Cell. Neurosci. 7:162. doi: 10.3389/fncel. 2013.00162

This article was submitted to the journal Frontiers in Cellular Neuroscience.

Copyright (C) 2013 Dickins and Salinas. This is an open-access article distributed under the terms of the Creative Commons Attribution License (CC BY). The use, distribution or reproduction in other forums is permitted, provided the original author(s) or licensor are credited and that the original publication in this journal is cited, in accordance with accepted academic practice. No use, distribution or reproduction is permitted which does not comply with these terms. 